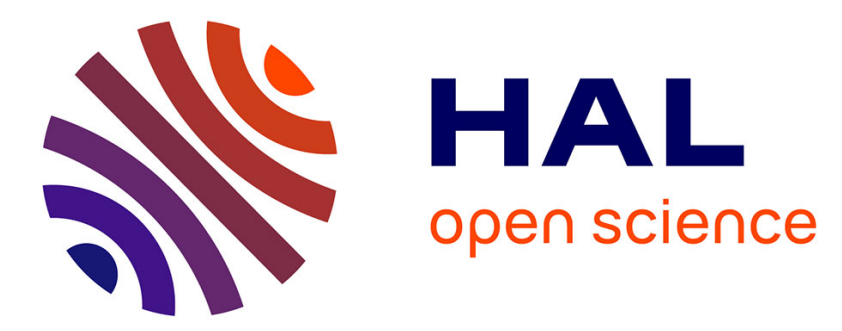

\title{
A Process Based Methodology to Evaluate the Use of PLM Tools in the Product Design
}

Angelo Corallo, Mariangela Lazoi, Antonio Margarito

\section{To cite this version:}

Angelo Corallo, Mariangela Lazoi, Antonio Margarito. A Process Based Methodology to Evaluate the Use of PLM Tools in the Product Design. 12th IFIP International Conference on Product Lifecycle Management (PLM), Oct 2015, Doha, Qatar. pp.125-133, 10.1007/978-3-319-33111-9_12 . hal01377435

\section{HAL Id: hal-01377435 \\ https://hal.inria.fr/hal-01377435}

Submitted on 7 Oct 2016

HAL is a multi-disciplinary open access archive for the deposit and dissemination of scientific research documents, whether they are published or not. The documents may come from teaching and research institutions in France or abroad, or from public or private research centers.
L'archive ouverte pluridisciplinaire HAL, est destinée au dépôt et à la diffusion de documents scientifiques de niveau recherche, publiés ou non, émanant des établissements d'enseignement et de recherche français ou étrangers, des laboratoires publics ou privés. 


\title{
A process based methodology to evaluate the use of PLM tools in the Product Design
}

\author{
Angelo Corallo $^{1}$, Mariangela Lazoi ${ }^{1}$, Antonio Margarito ${ }^{1}$ \\ ${ }^{1}$ Dipartimento di Ingegneria dell'Innovazione, Università del Salento, Italy \\ angelo.corallo@unisalento.it \\ mariangela.lazoi@unisalento.it \\ antonio.margarito@unisalento.it
}

\begin{abstract}
The product design requires the interaction of several disciplines and the use of a wide set of PLM tools. They are used both to design the product elements and also, to manage product data and information that are generated. For company working as ETO (EngineeringToOrder), the complexity increases. Generally, customers requires a certification of the design process and a clear and formalized workflow of approval and validation. The paper describes a methodology for evaluating the use of PLM tools in the design process of products. The proposed methodology aims to be an objective tool able to catch information of the impact of ICT directly from the processes using them. Techniques specific of the Business Process Management discipline have been used. Phases and indicators of the methodology can be applied to analyze the product design process in different context.
\end{abstract}

Keywords: PLM, Design Process, Manufacturing Company, Indicators, Process Simulation

\section{Introduction}

The design of product architecture and related physical components is very critical for the development of a new product. Accurately design the product, its physical components and how to assembly them in the architecture, it's a critical activity for companies. A worst design impacts on the product manufacturing. Changes in the manufacturing phase requires higher cost for the companies.

The design of product is relevant to avoid errors in the next lifecycle phases. ICT are used to support the design of each components and of the architecture along the lifecycle. For the scope of the paper, all the software that can used in the lifecycle of a product to manage and create data and workflow are specified as PLM tools.

Based on these premises, the study wants to propose a methodology to evaluate the benefits and impacts of the PLM tools used in the product design process. The proposed methodology aims to be an objective tool able to catch information of the impact of ICT directly from the processes using them. The methodology combines business processes modelling, data collection, statistical analysis and process 
simulation to create a set of indicators able to provide a complete picture on the use of PLM tools.

The results of the methodology aims to be used by managers to take decisions about policy and changes to be applied in companies and also, by theoretical that can apply parts or the whole methodology in other studies.

Background, research design and methodology steps are described in the paper.

\section{Background}

Ulrich and Eppinger [1] have defined the new product development process as "a sequence of phases and activities executed by the company to conceptualize, design and commercialize a product". Many of these activities are mainly intellectual and organizational more than physical or related to the product structure. In the detail design is realized the complete geometrical specification and the materials and the product tolerances are selected and specified. Furthermore, in those design phases, also, the design of the manufacturing process is established.

The ICT plays an important role in the communication, information exchange and integration leading the new product development process. The most advanced techniques of management and design are not the only determinants to obtain performance superiority in a new product, high performances in the whole organization and in the management are needed. The competitiveness of a firm is based on how the products are made in terms of quality, efficiency, speed [2] and cost [1].

The information is a fundamental element to manage a new product development process. A new product is realized through a net of information among different actors involved in different function and in collaboration with the network. In this view, the innovation process and the new product development one become more intensive and complex proportionally to the thickness of the relationships and information net. The firms have to manage an increasing quantity of information, coming from different actors that have to be aligned and integrated in a way to converge toward the final objective that is to realize a new product [2].

The product model including its architecture and physical elements, is realized in computer aided design (CAD) systems but also other systems (i.e. Computer Aided Technologies, CAX) are used to define engineering, manufacturing or testing data. In many companies, all the data generating by the CAD systems together with others product data (e.g. the bill of material - BOM) are integrated and available in PDM systems that store data and information about the product and its elements. They can be simple repository of information and users manually search and access to the information required or can provide workflows and other tools to manage the product data. [3]

In companies producing complex products and requiring the collaboration of several external actors or separated plants of the same firm, the tendency is to use a product lifecycle management strategy with the aim to trace and manage all the activities and flows of information and data during the product development process and later in the support activities [4]. The product lifecycle management (PLM) 
strategy involves the integration among individuals, organization and ICT systems to reach the best results [5] and all the external actors (i.e. customers, suppliers, partners etc.) are involved and integrated during the product lifecycle.

The role of processes in PLM is relevant as described in Schuh et al. [6] and Budde et al. [7]. Through processes, products evolve along the lifecycle and feedbacks (e.g. lesson learned and best practice) are diffused among the organizational practices. Different researchers have studied the relevance of processes in the product lifecycle. Messaadia et al [8] have explored the System Engineering processes to model PLM and concluded that this approach is complimentary to PLM to address the systems technology. Etienne et al [9] have proposed an interoperability platform based on product processes organizations. Schulte [10] instead has proposed a methodology to better integrate the customers' requirements of actual or attended products in the PLM functions, processes and metadata. As highlighted by Rangan et al [11], PLM processes need further exploration and a "cultural change management" is required in order to optimize organizational processes rather than individual benefits.

Focusing on companies working in complex sectors, there are specific case studies analyzing the aerospace and automotive sectors. For the aerospace sector, relevant studies are: 1) Alemanni et al. [5], which propose a KPI framework to test the adoption of a PLM tool, validated in an aerospace and defence company and 2) Lee et al. [12], which discuss two case studies from the aviation MRO companies in Singapore that stress the high potentiality of PLM applications. In the automotive sector, the study of Tang \& Qian [13] needs a citation: it illustrates the PLM implementation among an OEM and its suppliers highlighting practices and characteristics.

Therefore, several researchers have argued on the relevance of product design process and on the elements and tools characterizing its working and performance.

\section{Research Method}

Based on the previous background, the paper wants to describe the development and application of an integrated solution for the evaluation of the use of PLM tools in the product design process. The development and deployment of the solution is focus on a BPM based methodology.

The aim is to provide an answer to the main research question:

- How to evaluate the use of PLM tools in the product design process?

To answer at the research question, the used technique analyze the business process performance. Processes related to the product design have been chosen. The set of tools used and data in input and output have been highlighted. BPM has been used as reference. The study has required the collection and elaboration of data and information that have been represented using the software ARIS Business Architect 7.1. This software is suitable to design, analyze and simulate organizational processes.

The study is based on an action research led by an inductive approach in which problems and solutions have been established participating to and observing the organizational practices [14]. Research activities are carried out by an integrated team 
of University researchers and industrial engineers. The integrated team has designed the methodology and tested it in a company context.

\section{Study Results}

\subsection{Some remarks}

The study has been designed with the aim to evaluate the impact of PLM tools on Detailed Design process performances. It has been carried out with the initial aim to assess if the PLM Framework proposed by Corallo et al [15] can be used as starting reference for process and technology performances evaluation in the PLM domain.

In order to assess the impact that PLM tools can have on engineering process performances, the study is focused on the design process.

In the development of the methodology, two programs have been selected. The first one is mainly supported by an integrated PLM system (e.g. Enovia, Teamcenter), while the second one is mainly supported by a set of legacy systems and manual workflow approval.

The solution has been realized specifying and highlighting some common elements between the two programs:

- Scope of the process and related outputs;

- Focus on the same product component;

- Competencies of the involved employees.

The two programs differ instead by maturity level, ICT technologies used and role played by the companies in the supply chain. These differences affects the Detailed Design process implementations with some specific activities and sub-processes respect the whole process.

\subsection{The proposed methodology}

A methodology has been designed and tested to answer at the main research question. It is composed of four areas and seven steps (Fig. 1): 


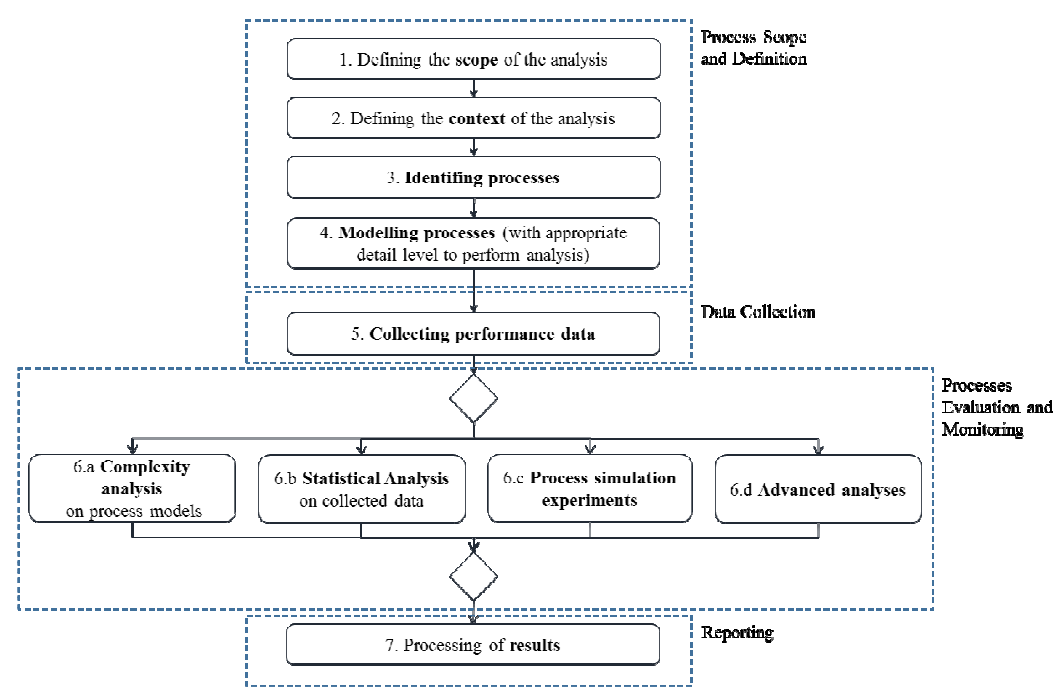

Fig. 1. Methodology Areas and Steps.

The first area is "Process Scope and Definition". The aim is to understand the company environment and problems, to design the reference processes and to identify the key users. For the modelling of the process is chosen the BPMN standard. The second area is "Data Collection". Data for the next steps are collected. The third area is "Processes Evaluation and Monitoring" that sets and performs different types of analysis useful to reach the study aims. Finally, the last area is "Reporting" for elaborating the final consideration on performance and comparing them.

In the next sub-sections, the attention is on the central areas of the methodology (i.e. the second and third ones). The right implementation is fundamental and core to reach the results.

\subsubsection{Data Collection}

Data are collected using an open-ended questionnaire administered in a group of designers, analysts and heads of department. Data are about the time required for the activities and the probabilities in the gateway. At the interviewees, it is presented the model of the process in which are involved.

The time collected for each activity has been shared in four types:

- Processing Time - Time necessary to process an activity;

- Orientation Time - Time required to become familiar with carrying out the activity. Includes the times to retrieve information on each activity.

- Static wait time - This is the time that must elapse before an activity can be processed (e.g. if a function cannot be processed until a work piece has cooled down or a contract cannot be signed until an essential response has been received).

For each time type, it has been asked to declare the minimum, maximum and average values. 
Furthermore, specific questions have been asked to express the probability of an event or a decision (e.g. approval rate). For each gateway, in fact, it has been asked to state frequency indicators values for:

- $\%$ of positive results of a check

- $\%$ of negative results of a check

- number of checks

The total number of activities analyzed for testing the methodology are 76.

\subsubsection{Process Evaluation and Monitoring}

Based on the previous collected data, four type of analyses have been designed and performed: complexity analysis of processes, statistical analysis of collected data, process simulations and advanced analyses.

\subsubsection{Complexity analysis of processes}

To compare processes, a quantitative indication of the structural complexity is provided. This analysis can provide a measure of how and how much the processes differ. These indicators are calculated observing the flow and type of activities and provides a direct, immediate and simplified picture of the process. Three sets of indicators are designed:

- $\quad$ Structure indicators provides a synthesis of structural features of the process.

- Degree of Computerization Indicators provides a synthesis of the use of IT systems and paper-based documents in the execution of the activities.

- $\quad$ Co-Occurence Indicators provides a synthesis of the number of parallel flows executed and represented in the process.

The details of the indicators for each sets are listed in the following table:

Table 1. Complexity Analysis Indicators.

\begin{tabular}{cl}
\hline Id & \multicolumn{1}{c}{ Indicators } \\
\hline Structure Indicators \\
1 & $\mathrm{~N}^{\wedge}$ Activities and Sub-Processes \\
2 & $\mathrm{~N}^{\wedge}$ Activities (no sub-processes) \\
3 & $\mathrm{~N}^{\wedge}$ Linked Sub-Processes \\
4 & $\mathrm{~N}^{\wedge}$ Decisional Gate (exclusive gateway) \\
5 & $\mathrm{~N}^{\wedge}$ Roles of Internal Actors \\
6 & $\mathrm{~N}^{\wedge}$ IT systems used \\
Degree of Computerization Indicators \\
$\quad$ High Computerization \\
7 & $\mathrm{~N}^{\wedge}$ Activities enabled by an IT system \\
8 & $\mathrm{~N}^{\wedge}$ Activities enabling an IT system \\
& Low Computerization \\
9 & $\mathrm{~N}^{\wedge}$ Activities with paper-based input \\
10 & $\mathrm{~N}^{\wedge}$ Activities with paper-based output \\
\hline
\end{tabular}




\begin{tabular}{ll}
\hline Co-Occurence Indicators \\
12 & $\mathrm{~N}^{\wedge}$ Activities Flow in co-occurrence (parallel gateway) \\
13 & $\mathrm{~N}^{\wedge}$ Activities Flow in co-occurrence through an IT system \\
14 & $\mathrm{~N}^{\wedge}$ Activities Flow in co-occurrence through multi-actors \\
\hline
\end{tabular}

The results of the complexity analysis are integrated with the results of the following analysis, to have a complete picture on the Detailed Design process performance.

\subsubsection{Statistical Analysis}

The statistical relationship among the collected data is explored. The statistical analysis aims to evaluate the relationships between the different types of time that impact on a design process. These relationships can be used to suggest lines of intervention and action to be applied for improving the design process.

The analysis have been realized on two groups for each program:

- $\quad$ on the total of activities data (76 total activities)

- $\quad$ only on the data of the activities performed by the role designers (only 18 activities)

The considered variables are:

- $\quad$ Processing Time

- Orientation Time

- $\quad$ Static Wait Time

In the correlation analysis, the relationships between two variables is explored.

The Experimental Design, instead, evaluates the effect of a variable on another; in particular, it evaluates if the existence of the independent variable impact on the behavior of the dependent variable.

Finally, the multiple regression analysis evaluates the relationship (impact) of a group of variables on another considered as dependent.

\subsubsection{Process Simulation}

The process simulation allows to forecast the process behavior in advance respect the process implementation by analyzing performance of its virtual representation (the process model). With the simulation, it is possible to explore and evaluate new management policies, minimize a cost function or maximize performances, properly allocate resources to tasks, identify bottlenecks and delay causes, etc.

Generally, to run simulation experiments, real data, statistical data or a mix of both can be used.

In the study, data collected from interviews have been used for the process simulation. The scope has been to get comprehensive information on performances of the Detailed Design process on the basis of data collected from interviews.

For the simulation analysis, the module Business Simulator of ARIS Business Architect has been used. The results of the simulation are based on a duration of the 
Detailed Design process of 100 days. The run of simulation has been launched, setting up a duration of 100 days.

The main quantitative indicators from simulation experiments are (Tab. 2):

Table 2. Simulation Quantitative Indicators.

\begin{tabular}{l}
\hline Measure \\
\hline Total duration time \\
[for design and final release of drawings/3D models] (man-hours) \\
Total design time \\
(man-hours) \\
Total approval time \\
[includes Configuration Control approval] (man-hours) \\
Configuration Control approval time \\
(man-hours) \\
Periodic Review Meetings \\
(man-hours) \\
Output quality (RRD number) (for the entire product) \\
\hline
\end{tabular}

Furthermore, graphic representation can be consulted on:

- Number of Detailed Design Process created and concluded in 100 days

- Distribution of Static Wait Time along the activities

- Distribution of Orientation Time along the activities

- Distribution of Processing Time along the activities

- Oltre agli indicatori precedenti sono stati grafici che rappresentano:

During the simulation design and run, feedbacks related to the use of the software have been collected to support replication of the study.

\subsubsection{Advanced Analysis}

In order to evaluate the output quality of the Detailed Design process we focused on the number of RRD (Drawing Change Requests) raised by manufacturing in a specific time interval (the same interval taken into account for Event Data Analysis) have been observed for each program. The number of RRD can provide information about the quality of a design process. A low number of RRD means that the design process is effective and efficient.

The analysis of RRD requests give us a quantitative evaluation of the quality of outputs in the design processes.

\section{Conclusion}

Based on an empirical application, the paper describes a methodology for evaluating the impact of PLM tools on design process using BPM techniques. It is a conceptual paper. A methodology is proposed and steps and indicators are described. 
The methodology and its parts are very general and can be applied also in other companies and sectors. In each application, the process features and flow will change because are dependent from the context. Steps and indicators proposed with the methodology are not dependent from the context and can be general used.

The methodology has been tested in two programs and some interesting results emerge from the statistical analysis. In fact, a general observation has been that in the first program where a PLM is used, the reduction of the static wait time has a positive effect on the processing and also on the orientation time. For the second program, there isn't a dependency among these variables. Some results further statistical results are: 1) the type of program doesn't impact on the processing time; 2) the type of program instead impacts on orientation time and static wait time because change the work organization; 3) the static wait time impacts on the processing time.

An interested, observed result is also, that considering together the processing time and the static wait time, if they simultaneously increase also the orientation time increases. A possible meaning could be that long processing time (e.g. for complex components) requires long static wait time to upload parts slowing down the retrieval of information. The quantity of information (the orientation time) could be proportional with the part complexity.

The management can use these results to act on a specific time for having the desired consequence.

The dimension of the sample for the statistical analysis is perhaps not so big and further validation on larger data sets can reinforce their applications.

Future papers will describe the application of the methodology and the results for each analysis. The following study will extend the validity of the methodology.

\section{References}

1. Ulrich, K.T. and Eppinger, S.D., (2008), Product Design and Development, McGraw Hill Education, Singapore

2. Clark, K.B. and Wheelright, S.C. (1995). The Product Development Challenge: Competing Through Speed, Quality, and Creativity, Harvard Business School Press

3. Grieves, M., (2006) Product Lifecycle Management: Driving the Next Generation of Lean Thinking. McGraw-Hill, New York, State

4. Garetti, M., Terzi, S., Bertacci, N., Brianza, M., (2005), Organisational change and knowledge management in PLM implementation, International Journal of Product Lifecycle Management, 1 (1), pp. 43-51

5. Alemanni, M., Grimaldi, A., Tornincasa, S. and Vezzetti, E. (2008). Key performance indicators for PLM benefits evaluation: The Alcatel Alenia Space case study, Computers in Industry, 59, 833-841

6. Schuh, G., Rozenfeld, H., Assmus, D., Zancul, E., (2008), Process oriented framework to support PLM implementation. Computers in Industry, 59 (2-3), pp. 210-218.

7. Budde, O., Schuh, G., Uam, J., (2010), Holistic PLM Model - Deduction of a Holistic PLM-Model from the General Dimensions of an Integrated Management, International Conference on Product Lifecycle Management, Bremen, Germany 
8. Messaadia, M., Jamal, M.H., Sahraoui, AEK, (2005), Systems Engineering Processes Deployment for PLM, International Conference on Product Lifecycle Management, Lyon, France.

9. Etienne, A., Guyot, E., Van Wijk, D., Roucoules, L., (2011), Specifications and development of interoperability solution dedicated to multiple expertise collaboration in a design framework, International Journal of Product Lifecycle Management, 5 (2), pp. 272-294.

10. Schulte, S., (2009), Customer centric PLM: integrating customers' feedback into product data and lifecycle processes, International Journal of Product Lifecycle Management, 3 (4), pp. 295- 307.

11. Rangan, R.M., Rohde, S.M., Peak, R., Chadha, B., and Bliznakov, P., (2005), Streamlining Product Lifecycle Processes: A Survey of Product Lifecycle Management Implementations, Directions, and Challenges, Journal of Computing and Information Science in Engineering, 5 (3), pp. 227-237.

12. Lee, S.G., Ma, Y.-S., Thimm, G.L., Verstraeten, J., (2008), Product lifecycle management in aviation maintenance, repair and overhaul, Computers in Industry, 59 ( 2 3), pp. 296-303.

13. Tang, D., Qian, X., (2008), Product lifecycle management for automotive development focusing on supplier integration. Computer in Industry, 59 (2-3), pp. 288-295.

14. Bryman A, Bell E. (2007), Business Research Methods, Oxford University Press, Oxford.

15. Corallo Angelo, Lazoi Mariangela, Margarito Antonio, Pinna Davide, (2013), Developing a PLM Framework in an energy company: a case study, Proceeding of Conference 10th International Conference on Product Lifecycle Management, Nantes, July; 